Archive for

Organic Chemistry

Arkivoc 2018, part ii, 280-287

\title{
Synthesis and application of a novel bis-1,2,3-triazole ligand containing a 2,2'-bipyrrolidine core
}

\author{
Stephen E. Motika and Xiaodong Shi* \\ Department of Chemistry, University of South Florida, Tampa, FL 33620, USA \\ Email: xmshi@usf.edu
}

Dedicated to Dr. Kenneth Laali for his outstanding contributions in the field of synthetic organic chemistry

Received 08-28-2017

Accepted 12-15-2017

Published on line 01-28-2018

\section{Abstract}

Herein, we describe the synthesis of a novel bis-1,2,3-triazole ligand which contains an internal $\mathrm{N}$-alkylated 2,2'-bipyrrolidine linker. By using simple starting materials, the ligand could be generated in good yield through several synthetic steps. To investigate the potential for the application of this ligand in transition metal catalysis, we generated a bis-Au(I) complex in nearly quantitative yield and examined its reactivity in the context of alkyne hydration. Both alkyl and aryl terminal alkynes could be efficiently converted to their corresponding ketones in nearly quantitative yields with only $1 \%$ catalyst loading under mild conditions.

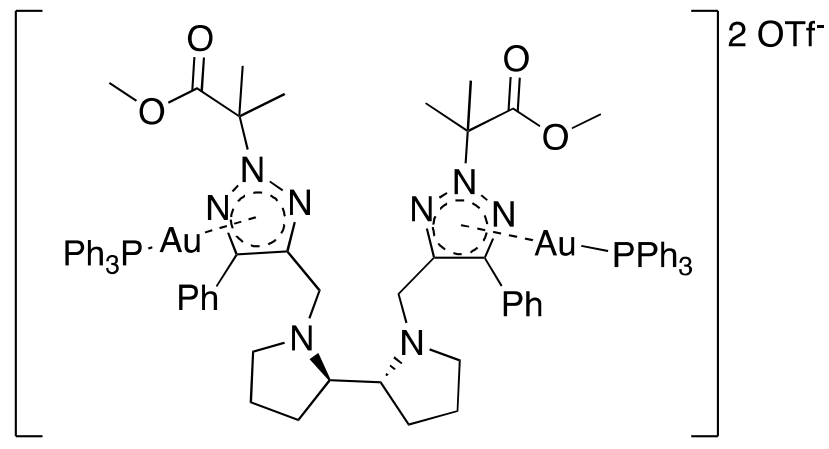

Catalytically Competent for Alkyne Hydration

Keywords: 1,2,3-Triazole, gold catalysis, alkyne hydration 


\section{Introduction}

Over the past century, ligand design has been integral to the realization of new catalytic approaches relying on transition metals. In many cases, subtle changes in ligand structure and electronic character have dramatic influences on the stability and reactivity of the metal to which it is bound. This intimate relationship between structure and reactivity has therefore been an impetus to pursue new ligand systems. Despite the structural complexity inherent to many effective classes of ligand, much of this work relies on the inherent properties of privileged small molecules, which when derivatized in unique ways, form structurally unique ligand scaffolds.

In the past decade, our group has found success in implementing functionalized 1,2,3-triazoles (TAs) as ligands for late transition metals. Thus far, we have demonstrated that these electron-poor heterocycles have a high affinity to bind to mid to late transition metals such as $\mathrm{Rh}^{1}{ }^{1} \mathrm{Pd},{ }^{2} \mathrm{Fe},{ }^{3} \mathrm{Ir},{ }^{4}$ and $\mathrm{Au} .{ }^{5-9}$ In the case of $\mathrm{Au}(\mathrm{I})$, neutral TA ligands can dramatically enhance the thermal stability and chemoselectivity of the Au-cation. ${ }^{10,11}$ In the absence of neutral secondary ligands or strong sigma-donating spectator ligands, Au-cation often decomposes to a metallic form through external reduction or disproportionation pathways. ${ }^{12}$ By harnessing the productive partnership between $\mathrm{Au}(\mathrm{I})$ and TA, we have broadened the scope of Au-catalysis by generating new catalyst libraries that offer broad electronic and structural range.

Our insight and background in TA synthesis and its metal coordination has naturally led us to consider new and abstract ligand systems containing this heterocycle. Furthermore, we were particularly interested in the prospect of a bis-TA ligand that could simultaneously accommodate two metal atoms, as described in Scheme 1. In the context of Au-catalysis, generating a new class of bis-Au(I) complexes may provide new avenues to access and productively utilize Au-Au intermediates. Additionally, the 2-coordinate nature of Au(I) would allow us to avoid the formation of chelation complexes. To establish this structural paradigm, we realized it would necessary to identify an adequate TA scaffold and linker. After considering several viable linkers, we chose to investigate the 2,2'-bipyrrolidine structure, as this would provide a mild synthetic platform hinging on $\mathrm{N}$-alkylation, a step easily conceived through an $\mathrm{S}_{\mathrm{N}} 2$ reaction. Moreover, a TA subunit containing a leaving group would be paramount to execute this design.

TA-Subunit
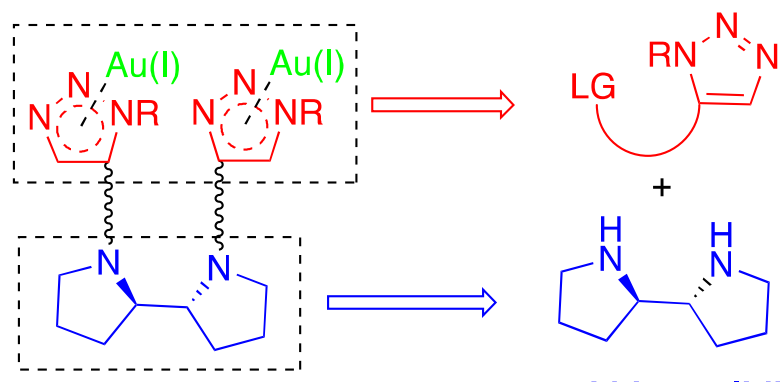

2 eq. $A u(I)$

2,2'-bipyrrolidine

Scheme 1. Basic design for the synthesis of bis-1,2,3-triazole-Au(I) complex.

\section{Results and Discussion}

As described in the introduction, our first task was to generate a TA subunit that would be poised for amination in the presence of 2,2'-pyrrolidine backbone. This would ultimately involve discerning a TA- 
synthesis that would easily allow the incorporation of a leaving group. With this in mind, we could easily adopt an adequate alkyne precursor for the formation of the heterocyclic core. As described in Scheme 2, alkyne $\mathbf{2}$ could be easily generated under typical alkyne-acylation procedures. From alkyne 2, we could efficiently access TA 3 through cycloaddition with $\mathrm{NaN}_{3}$ with good overall yield. The ester on TA 3 was then reduced to the corresponding alcohol using excess $\mathrm{LiAlH}_{4}$, which will be important for the generation of a good leaving group later. Following reduction, N2-alkylation was performed to give TA $\mathbf{5}$ in high yields and N2 selectivity. The N2 selectivity was confirmed by performing a series of 1D NOE experiments on the product obtained. This step was performed for two reasons, the first being to inhibit unwanted dimerization when the subsequent alkyl bromide is formed, and the second being to specifically investigate N1 or N3 binding with the Au-cation. Compound $\mathbf{5}$ was then treated with $\mathrm{PBr}_{3}$ at lower temperatures to give the key and final product, TA 6.

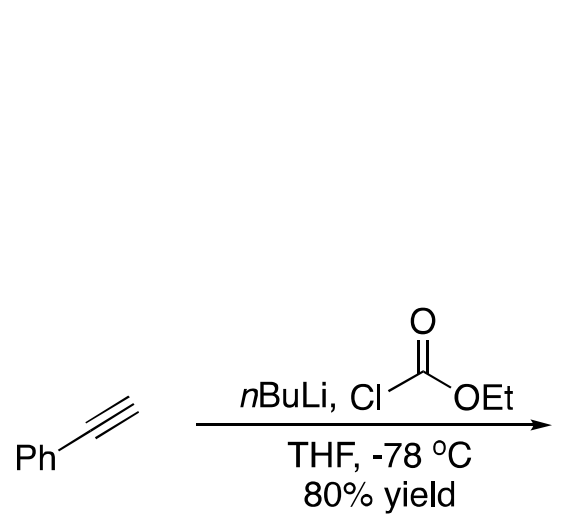

1
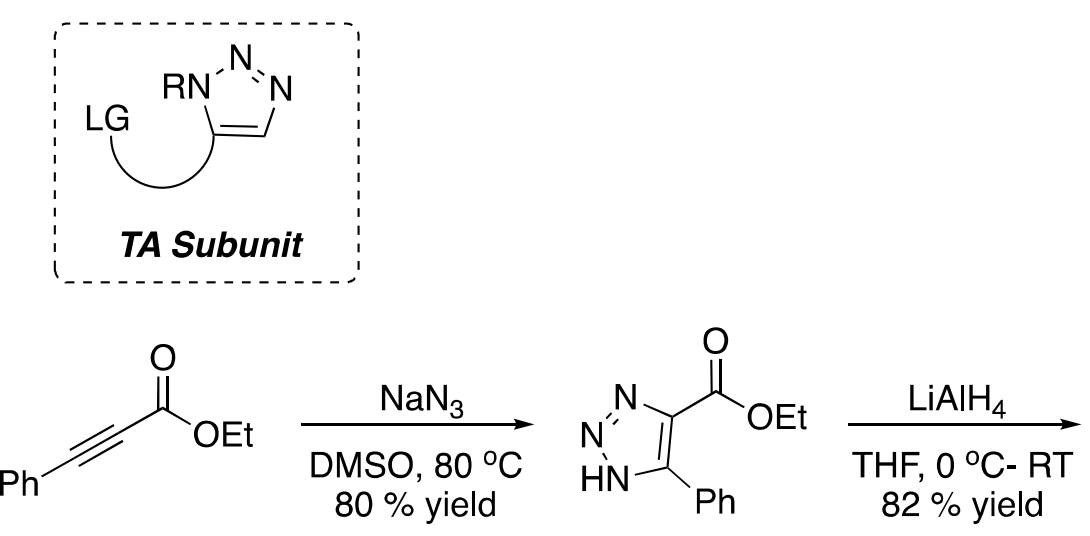

2

3

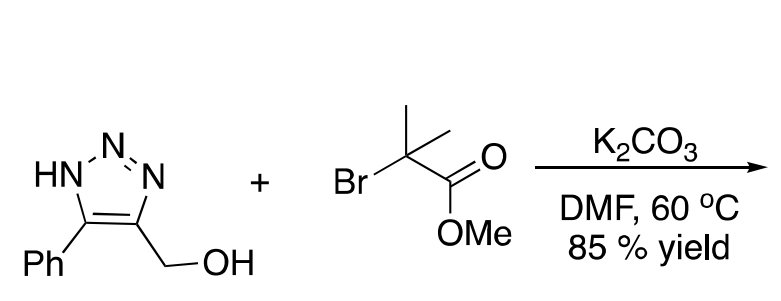

4

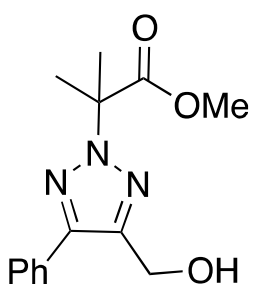

5

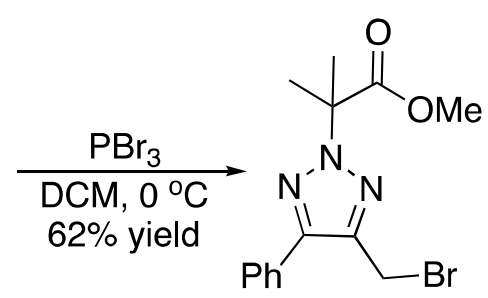

6

Scheme 2. Synthesis of TA subunit.

Following the successful synthesis of TA 6 , we proceeded with the di-N-alkylation of $\left(2 R, 2^{\prime} R\right)-2,2^{\prime}-$ bipyrrolidine as illustrated in Scheme 3. After a brief reaction screening, it was determined that treating the two components with potassium carbonate at room temperature in DCM efficiently provided target 7 in good yield. With the desired compound in hand, we then generated the bis-Au complex 8 by treating the ligand with two equivalents of $\mathrm{Ph}_{3} \mathrm{PAuCl}$ and two equivalents of AgOTf. Upon the addition of AgOTf, a white precipitate $(\mathrm{AgCl})$ could be seen almost immediately. The complex prepared through this step was characterized using ${ }^{1} \mathrm{H},{ }^{13} \mathrm{C}$, and ${ }^{31} \mathrm{P}$ NMR analysis. However, we have not been able to grow an adequate crystal for X-ray analysis. It is important to note that the broad nature of the NMR spectra for the complex suggests some dynamic bonding behavior in solution. This is likely due to the coalescence of a number of different regioisomer signals at room temperature. Nevertheless, the dramatic change in ${ }^{1} \mathrm{H}$ and ${ }^{13} \mathrm{C} N M R$ spectra are strongly indicative of some significant level of bonding interaction. Additionally, the difference in 
chemical shift ( $\delta 25.8 \mathrm{ppm}$ ) observed in the ${ }^{31} \mathrm{P}$ NMR signal relative to pure $\mathrm{Ph}_{3} \mathrm{PAuCl}(\delta 34.3 \mathrm{ppm})$ and $\mathrm{Ph}_{3} \mathrm{PAuOTf}$ ( $\delta 28.8 \mathrm{ppm}$ ) is a compelling result that strongly supports complex formation. ${ }^{10}$ At this point though, it is difficult to determine any specific binding motif in solution. It is also important to note here that the complex generated when using only one equivalent of $\mathrm{Ph}_{3} \mathrm{PAuCl}$ was quite unstable and clearly started to decompose upon work up and solvent removal.

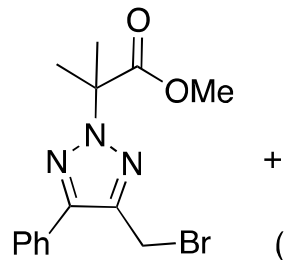

6

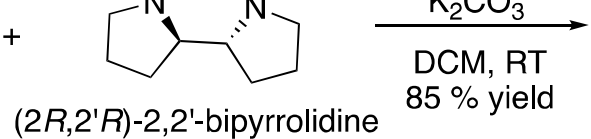

$\left(2 R, 2^{\prime} R\right)-2,2^{\prime}$-bipyrrolidine

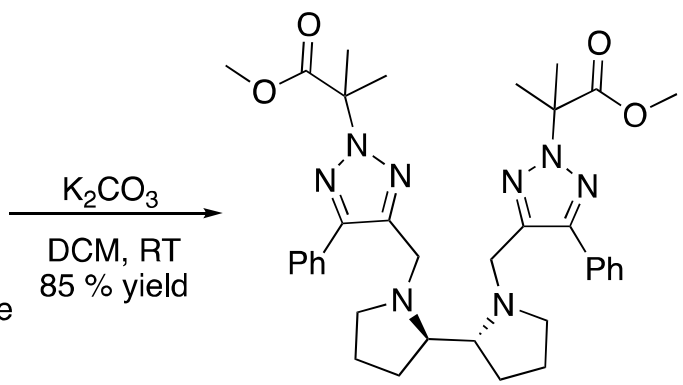

7

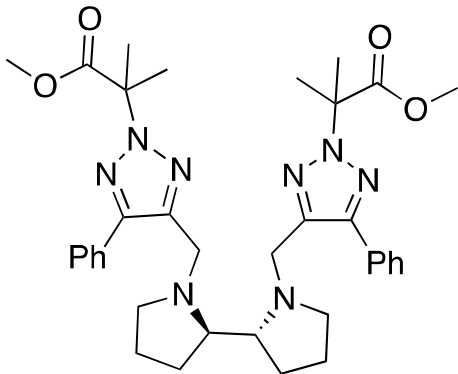

7
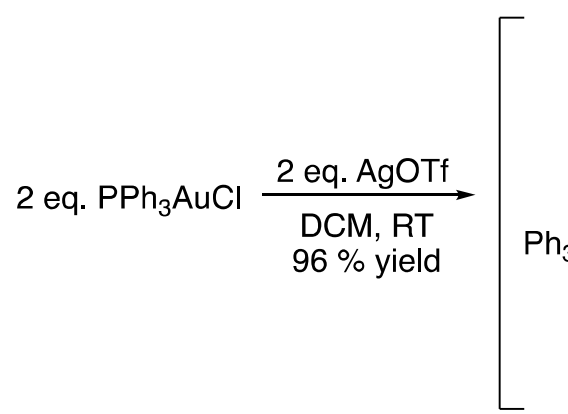

(n)

Scheme 3. Synthesis of bis-TA-ligand and complexation to $\mathrm{Au}(\mathrm{I})$.

Following the synthesis of complex 8, we next wanted to establish some catalytic activity. To accomplish this, we investigated terminal alkyne hydration under relatively mild conditions. At room temperature, very little alkyne hydration could be seen after 24 hours. However, as shown in Scheme 4, when the reaction temperature was raised to $50{ }^{\circ} \mathrm{C}$ both alkyl and aryl terminal alkynes could undergo hydration in almost quantitative yield. Interestingly, only the free ligand could be observed at the end of the reaction, which suggests that the Au-catalyst is decomposing upon reaction completion. This is perhaps due to a decomposition pathway resulting from competitive coordination from water or the resulting ketone product. Despite the decomposition of the catalyst observed upon complete conversion of the starting material, we were surprised to see such high efficiency given the presence of a tertiary amine within the ligand. In some cases, amines and thiols lead to $\mathrm{Au}(\mathrm{I})$-catalyst deactivation due to their high nucleophilicity. ${ }^{13}$ However , the bulkier tertiary amine and competitive coordination of other functional groups in the ligand is likely to inhibit deactivation to any great extent. 

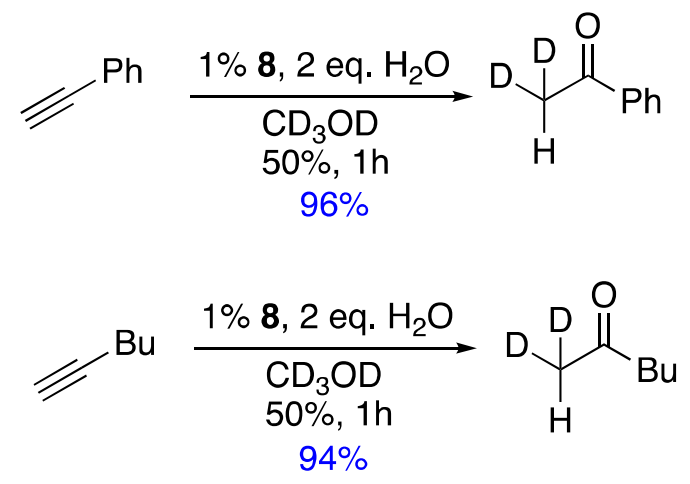

Scheme 4. Assessing catalytic activity in alkyne hydration.

\section{Conclusions}

As reported here, we have been able to synthesize a new bis-TA ligand which appeared to bind effectively to $\mathrm{Au}(\mathrm{I})$. Based on NMR data, the ligand is interacting with $\mathrm{Au}(\mathrm{I})$ in a very dynamic fashion. This catalyst exhibits good thermal stability and high efficiency in the hydration reaction of terminal aryl and alkyl alkynes, which proves that the tertiary amines within the ligand do not lead to $A u(I)$ deactivation. In summary, we believe these results may give way to new ligand-metal paradigms that will offer insight to new methodological advances.

\section{Experimental Section}

General. All reactions were carried out under an atmosphere of nitrogen using oven or flame dried glassware and standard syringe/septa techniques. Unless noted, all commercial reagents and solvents were used without further purification. Flash column chromatography was performed on 230-430 mesh silica gel. Analytical thin layer chromatography was performed with pre-coated, glass-baked plates $(250 \mu)$ and visualized by fluorescence or charring with potassium permanganate stain. Melting point were recorded on Mel-Temp. ${ }^{1} \mathrm{H}$ NMR, ${ }^{13} \mathrm{C}$ NMR and ${ }^{31} \mathrm{P} N M R$ spectra were recorded on an Agilent $400 \mathrm{MHz}$ spectrometer. Chemical shifts for starting materials and products were reported relative to tetramethylsilane $(0.00 \mathrm{ppm})$ or $\mathrm{CD}_{3} \mathrm{OD}(3.31 \mathrm{ppm})$ for ${ }^{1} \mathrm{H}$ NMR data, $\mathrm{CDCl}_{3}$ (77.0 ppm) or $\mathrm{CD}_{3} \mathrm{OD}$ (49.9) for ${ }^{13} \mathrm{C} \mathrm{NMR}$ and $\mathrm{H}_{3} \mathrm{PO}_{4} / \mathrm{D}_{2} \mathrm{O}$ for ${ }^{31} \mathrm{P}$ NMR data. Data are presented as follows: chemical shift $(\mathrm{ppm})$, multiplicity $(\mathrm{s}=$ singlet, $\mathrm{d}=$ doublet, $\mathrm{t}=\mathrm{triplet}$, $\mathrm{dd}=\mathrm{doublet}$ of doublets, $\mathrm{m}=$ multiplet, $\mathrm{br}=$ broad), coupling constant $\mathrm{J}(\mathrm{Hz})$ and integration. ESI-MS spectra were collected using a Thermo Scientific Orbitrap Q Extractive Plus (Bremen, Germany) in the positive ion mode. The samples were infused with a flow rate of $10 \mu \mathrm{L} / \mathrm{min}$ and sprayed at a high voltage of $5 \mathrm{kV}$.

Synthesis of ethyl 3-phenylpropiolate (2). To a nitrogen flushed round bottom flask with a solution of phenylacetylene $(2.04 \mathrm{~g}, 20 \mathrm{mmol})$ in distilled THF $(20 \mathrm{~mL})$ at $-78^{\circ} \mathrm{C}$ was added $n$-BuLi $(8.4 \mathrm{~mL}, 21 \mathrm{mmol}, 2.5 \mathrm{M}$ in hexane) dropwise. The solution was stirred at this temperature for approximately 1 hour. After this time, ethyl chloroformate $\left(2.3 \mathrm{~mL}, 24 \mathrm{mmol}\right.$, neat) was added at $-78{ }^{\circ} \mathrm{C}$. The solution stirred at this temperature and was monitored by TLC. Complete conversion could be observed after approximately 2.5 hours. Upon completion, the reaction was quenched through the addition of a saturated solution of $\mathrm{NH}_{4} \mathrm{Cl}$ at room 
temperature. The organic layer was extracted with ethyl acetate $(3 \times 20 \mathrm{~mL})$ and dried using sodium sulfate. This solution was filtered through a plug of cotton and concentrated by rotary evaporation. The crude reaction product was then purified using column chromatography (gradient from 20:1 to 5:1 hexanes: ethyl acetate) to give $2.8 \mathrm{~g}$ (80\% yield) of the alkyne as a clear oil. The ${ }^{1} \mathrm{H}$ and ${ }^{13} \mathrm{C}$ NMR spectra for this internal alkyne matched identically to the many previous reported syntheses. ${ }^{14,15,16}$

Synthesis of ethyl 5-phenyl-1H-1,2,3-triazole-4-carboxylate_(3). To a gently stirred solution of alkyne 2 (1.75 g, 10 $\mathrm{mmol})$ in DMSO $(20 \mathrm{~mL}, 0.5 \mathrm{M})$ was added $\mathrm{NaN}_{3}(1.9 \mathrm{~g}, 30 \mathrm{mmol})$ in four portions over 20 minutes. Once the $\mathrm{NaN}_{3}$ was completely dissolved, the unsealed reaction was heated to $80^{\circ} \mathrm{C}$ for 8 hours. Upon completion, distilled water was slowly added to the reaction followed by slow and incremental addition of $1.0 \mathrm{M} \mathrm{HCl}$ until a $\mathrm{pH}$ of 1 was reached. The solution was then extracted using DCM (3 $30 \mathrm{~mL})$. The organic layer was washed with brine and dried over sodium sulfate. Following filtration and concentration of the organics by rotary evaporation, the crude product was purified via recrystallization (5:1 Hexanes: DCM) to give triazole 3 (1.7 g, $80 \%)$ as an off-white powder. mp 92-93 ${ }^{\circ} \mathrm{C} .{ }^{1} \mathrm{H}-\mathrm{NMR}\left(400 \mathrm{MHz} ; \mathrm{CDCl}_{3}\right): \delta 7.79(\mathrm{~m}, 2 \mathrm{H}), 7.40(\mathrm{~m}, 3 \mathrm{H}), 4.36(\mathrm{q}, J$ $6.9 \mathrm{~Hz}, 2 \mathrm{H}), 1.28(\mathrm{t}, J 7.2 \mathrm{~Hz}, 3 \mathrm{H}) ;{ }^{13} \mathrm{C}-\mathrm{NMR}\left(101 \mathrm{MHz} ; \mathrm{CDCl}_{3}\right): \delta 161.2,129.7,129.2,128.2,61.6,13.9 . \mathrm{HRMS}$ Calculated for $\mathrm{C}_{11} \mathrm{H}_{12} \mathrm{~N}_{3} \mathrm{O}_{2}[\mathrm{M}+\mathrm{H}]^{+}: 218.0924$, Found: 218.0930 .

Synthesis of (5-phenyl-1H-1,2,3-triazol-4-yl)methanol (4). ${ }^{17} \mathrm{~A}$ solution of $3(1.5 \mathrm{~g}, 7 \mathrm{mmol})$ in THF $(23 \mathrm{~mL}, 0.3 \mathrm{M})$ was cooled to $0{ }^{\circ} \mathrm{C}$ in an ice bath. $\mathrm{LiAlH}_{4}(380 \mathrm{mg}, 10 \mathrm{mmol})$ was then added to the solution in four portions over 20 minutes. The reaction mixture was then warmed to room temperature and stirred for 30 minutes. Upon completion, as confirmed by TLC, the reaction was then cooled back down to $0{ }^{\circ} \mathrm{C}$ and quenched through dropwise addition of a saturated ammonium cloride solution. The reaction mixture was then acidified by addition of $1.0 \mathrm{M} \mathrm{HCl}$. This was then extracted using DCM $(3 \times 30 \mathrm{~mL})$. The organics were then dried over sodium sulfate, filtered and concentrated via rotary evaporation. The crude reaction material was then purified using trituration and recrystallization (approximately 3:1 Hexanes: DCM) to give triazole 4 (1.0 g, $82 \%$ ) as a white solid. m.p. $133-134{ }^{\circ} \mathrm{C} .{ }^{1} \mathrm{H}-\mathrm{NMR}\left(400 \mathrm{MHz} ; \mathrm{CD}_{3} \mathrm{OD}\right): \delta$ 7.59-7.57 (m, 2H), 7.38-7.34 (t, J 7.5 Hz, $\left.2 \mathrm{H}\right)$, 7.26-7.24 (m, 1H), 4.65 (s, 2H); ${ }^{13} \mathrm{C}-\mathrm{NMR}\left(101 \mathrm{MHz} ; \mathrm{CD}_{3} \mathrm{OD}\right): \delta 143.2,140.7,132.3,128.7,127.1,126.9,54.6$. Calculated for $\mathrm{C}_{9} \mathrm{H}_{10} \mathrm{~N}_{3} \mathrm{O}[\mathrm{M}+\mathrm{H}]^{+}: 176.0818$, Found: 176.0821 .

Synthesis of methyl 2-[4-(hydroxymethyl)-5-phenyl-2H-1,2,3-triazol-2-yl]-2-methylpropanoate (5). A solution containing alcohol 4 ( $875 \mathrm{mg}, 5 \mathrm{mmol})$, methyl $\alpha$-bromoisobutyrate $(1.8 \mathrm{~g}, 10 \mathrm{mmol}$ ) and potassium carbonate $(1.37 \mathrm{~g}, 10 \mathrm{mmol})$ in DMF $(10 \mathrm{~mL}, 0.5 \mathrm{M})$ was heated to $60{ }^{\circ} \mathrm{C}$ for 6 hours. The reaction was cooled to room temperature and water $(20 \mathrm{~mL})$ was added. This solution was then extracted with diethyl ether $(3 \times 20 \mathrm{~mL})$ and dried over sodium sulfate. This mixture was filtered and concentrated using rotary evaporation. The crude product was then purified using column chromatography (gradient from 10:1 to 3:1 hexanes: ethyl acetate) to give $1.20 \mathrm{~g}$ (85\% yield) of triazole 5 as a viscous colorless oil. ${ }^{1} \mathrm{H}-\mathrm{NMR}\left(400 \mathrm{MHz} ; \mathrm{CDCl}_{3}\right): \delta 7.83-7.80(\mathrm{~m}, 2 \mathrm{H})$, 7.45-7.41 (m, 2H), 7.36 (dd, J 8.6, 6.1 Hz, 1H), $4.86(\mathrm{~s}, 2 \mathrm{H}), 3.69(\mathrm{~s}, 3 \mathrm{H}), 1.97(\mathrm{~s}, 6 \mathrm{H}) ;{ }^{13} \mathrm{C}-\mathrm{NMR}\left(101 \mathrm{MHz} ; \mathrm{CDCl}_{3}\right)$ : $\delta 172.4,145.5,143.8,130.4,128.7,128.3,127.5,67.8,56.2,52.9,25.3$. Calculated for $\mathrm{C}_{14} \mathrm{H}_{17} \mathrm{~N}_{3} \mathrm{NaO}{ }_{3}[\mathrm{M}+\mathrm{Na}]^{+}$: 298.1162, Found: 298.1164.

Synthesis of methyl 2-[4-(bromomethyl)-5-phenyl-2H-1,2,3-triazol-2-yl]-2-methylpropanoate (6). A solution of ester $5(1.10 \mathrm{~g}, 4 \mathrm{mmol})$ in $\mathrm{DCM}(10 \mathrm{~mL}, 0.4 \mathrm{M})$ was cooled to $0{ }^{\circ} \mathrm{C}$ under a stream of nitrogen gas. $\mathrm{PBr}_{3}(1.7$ $\mathrm{g}, 6.4 \mathrm{mmol}$ ) was then added to the solution dropwise. The reaction was then stirred at this temperature and monitored by TLC until completion. Upon completion, a saturated sodium bicarbonate solution was added to the reaction at $0{ }^{\circ} \mathrm{C}$. Once gas evolution was no longer apparent, water $(10 \mathrm{~mL})$ was added to the crude reaction mixture. This solution was then extracted using DCM $(3 \times 20 \mathrm{~mL})$. The organic extracts were then dried over sodium sulfate, filtered and concentrated. The crude reaction mixture was then purified using column chromatography (gradient from 12:1 to $6: 1$ hexanes: ethyl acetate) to give $835 \mathrm{mg}$ (62\% yield) of 
triazole 6 as a white solid. Mp 90-92 ${ }^{\circ} \mathrm{C} .{ }^{1} \mathrm{H}-\mathrm{NMR}\left(400 \mathrm{MHz} ; \mathrm{CDCl}_{3}\right): \delta 7.80$ (dd, J 8.2, $\left.1.1 \mathrm{~Hz}, 2 \mathrm{H}\right), 7.48-7.44(\mathrm{~m}$, $2 \mathrm{H}), 7.40-7.38(\mathrm{~m}, 1 \mathrm{H}), 4.66(\mathrm{~s}, 2 \mathrm{H}), 3.70(\mathrm{~s}, 3 \mathrm{H}), 1.98(\mathrm{~s}, 6 \mathrm{H}) ;{ }^{13} \mathrm{C}-\mathrm{NMR}\left(101 \mathrm{MHz} ; \mathrm{CDCl}_{3}\right): \delta 172.1,145.6,141.0$, $130.0,128.8,128.6,127.6,68.2,53.0,25.3,22.6$. Calculated for $\mathrm{C}_{14} \mathrm{H}_{17} \mathrm{BrN}_{3} \mathrm{O}_{2}[\mathrm{M}+\mathrm{H}]^{+}$: 338.0499, Found: 338.0499 .

Synthesis of dimethyl 2,2'-\{[(2,2'-bipyrrolidine)-1,1'-diylbis(methylene)]bis-(5-phenyl-2H-1,2,3-triazole-4,2diyl)\}bis-(2-methylpropanoate) (ligand 7). A solution of 6 (674 mg, $2 \mathrm{mmol}$ ), (2R,2'R)-2,2'-bipyrrolidine (265 $\mathrm{mg}, 1.9 \mathrm{mmol}$ ) and potassium carbonate $(410 \mathrm{mg}, 3 \mathrm{mmol})$ in DCM $(7 \mathrm{~mL}, 0.3 \mathrm{M})$ was stirred at room temperature. The reaction was monitored for completion using TLC. Upon completion, water $(10 \mathrm{~mL}) \mathrm{was}$ added and extractions using DCM $(3 \times 15 \mathrm{~mL})$ were performed. The organic layers were dried over sodium sulfate, filtered and concentrated. The crude reaction mixture was then purified using column chromatography (gradient from 5:1 to $1: 1$ hexanes ethyl acetate) to give $1.05 \mathrm{~g}$ ( $85 \%$ yield) of ligand 7 as a

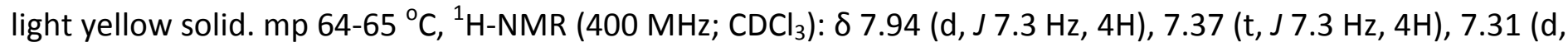
J $7.0 \mathrm{~Hz}, 2 \mathrm{H}), 3.97(\mathrm{~d}, J 12.8 \mathrm{~Hz}, 2 \mathrm{H}), 3.66(\mathrm{~s}, 6 \mathrm{H}), 3.51(\mathrm{~d}, J 12.8 \mathrm{~Hz}, 2 \mathrm{H}), 2.83(\mathrm{t}, J 7.6 \mathrm{~Hz}, 2 \mathrm{H}), 2.76(\mathrm{t}, J 6.5 \mathrm{~Hz}$, $2 \mathrm{H}), 2.28(\mathrm{td}, J$ 9.6, $6.8 \mathrm{~Hz}, 2 \mathrm{H}), 1.92(2 \mathrm{~s}, J 3.1 \mathrm{~Hz}, 12 \mathrm{H}), 1.77(\mathrm{~m}, 4 \mathrm{H}), 1.63(\mathrm{~m}, 4 \mathrm{H}) ;{ }^{13} \mathrm{C}-\mathrm{NMR}\left(101 \mathrm{MHz} ; \mathrm{CDCl}_{3}\right)$ : $\delta$ 172.5, 146.0, 142.8, 131.2, 128.3, 128.1, 127.9, 67.5, 64.8, 54.7, 52.8, 49.6, 26.1, 25.4, 25.2, 23.9. Calculated for $\mathrm{C}_{36} \mathrm{H}_{47} \mathrm{~N}_{8} \mathrm{O}_{4}[\mathrm{M}+\mathrm{H}]^{+}:$: 655.3715, Found: 655.3726 .

Synthesis of complex 8. Ligand $7(82 \mathrm{mg}, 0.125 \mathrm{mmol})$ and $\mathrm{Ph}_{3} \mathrm{PAuCl}(123 \mathrm{mg}, 0.25 \mathrm{mmol})$ were dissolved in $\operatorname{DCM}(625 \mu \mathrm{L}, 0.2 \mathrm{M})$ at room temperature. To this solution was added AgOTf $(64 \mathrm{mg}, 0.25 \mathrm{mmol})$. AgCl immediately precipitated out of solution as a white solid. This solution stirred for 2 hours followed by gravity filtration through two pipettes filled halfway with celite. The filtrate was then collected and concentrated to give a light yellow solid. Recrystallization was then performed to give $190 \mathrm{mg}$ (95\% yield) of complex 8 as an off-white solid. ${ }^{1} \mathrm{H}-\mathrm{NMR}\left(400 \mathrm{MHz} ; \mathrm{CDCl}_{3}\right): \delta 7.56-7.34(\mathrm{~m}, 38 \mathrm{H}), 4.49(\mathrm{~m}, 2 \mathrm{H}), 3.67(\mathrm{~s}, 7 \mathrm{H}), 3.39(\mathrm{~s}, 1 \mathrm{H}), 2.91(\mathrm{~s}$, $1 \mathrm{H}), 1.90(\mathrm{~m}, 22 \mathrm{H}) ;{ }^{13} \mathrm{C}-\mathrm{NMR}\left(101 \mathrm{MHz} ; \mathrm{CDCl}_{3}\right): \delta 172.1,134.1,133.9,133.8,132.4,129.6,129.5,129.4,129.2$, 129.1, 128.1, 127.8, 68.7, 53.1, 25.2; ${ }^{31} \mathrm{P}-\mathrm{NMR}\left(162 \mathrm{MHz} ; \mathrm{CDCl}_{3}\right): \delta 25.8$.

General procedure for alkyne hydration (Scheme 4). In an NMR tube, alkyne (phenylacetylene: $24 \mathrm{mg}, 0.24$ mmol; 1-hexyne: $20 \mathrm{mg}, 0.24 \mathrm{mmol})$ complex 8 (5 mg, $0.0024 \mathrm{mmol})$ and $p$-xylene $(25 \mathrm{mg}, 0.24 \mathrm{mmol}$, internal standard) were dissolved in deuterated methanol ( $0.6 \mathrm{~mL}, 0.4 \mathrm{M})$. The reaction was then heated to $50{ }^{\circ} \mathrm{C}$ and monitored every 10 minutes by ${ }^{1} \mathrm{H}$ NMR until completion.

\section{Acknowledgements}

We would like to acknowledge the financial support of the NSF (CHE-1619590), NIH(1R01GM120240-01) and NSFC (21629201).

\section{References}

1. Duan, H.; Sengupta, S.; Petersen, J. L.; Shi, X. Organometallics. 2009, 28, 2352-2355. http://pubs.acs.org/doi/full/10.1021/om8011163

2. Ye, X.; Xu, C.; Wojtas, L.; Akhmedov, N.;Chen, H.; Shi, X. Org. Lett. 2016, 18, 2970-2973. http://pubsdc3.acs.org/ doi/full/10.1021/acs.orglett.6b01319

3. Yan, W.; Ye, X.; Akhmedov, N. G.; Petersen, J. L.; Shi, X. Org. Lett. 2012, 14, 2358-2361. http://pubs.acs. org/doi/full/10.1021/ol300778e 
4. Cai, R.; Yan, W.; Bologna, M. G.; de Silva, K.; Finklea, H. O.; Petersen, J. L.; Shi, X. Org. Chem. Front. 2015, 2, 141-144.

http://pubs.rsc. /en/content/articlelanding/2014/qo/c4qo00281d\#!divAbstract

5. Motika, S. E.; Wang, Q.; Akmendov, N. G.; Wojtas, L.; Shi, X. Angew. Chem. Int. Ed. 2016, 55, 11582-11586. http://onlinelibrary.wiley.com/doi/ 10.1002/anie.201604986/full

6. Wang, Q.; Motika, S. E.; Akhmedov, N. G.; Petersen, J. L.; Shi, X. Angew. Chem. Int. Ed. 2014, 53, 54185422.

http://onlinelibrary.wiley.com/doi/10.1002/anie.201402614/abstract

7. Xi, Y.; Dong, B.; McClain, E. J.; Wang, Q.; Gregg, T. L.; Akhmedov, N. G.; Petersen, J. L.; Shi, X. Angew. Chem. Int. Ed. 2014, 53, 4657-4661.

http://onlinelibrary.wiley.com/doi/10.1002/anie.201310142/abstract

8. Cai, R.; Ye, X.; Sun, Q.; He, Q.; He, Y.; Ma, S. *; Shi, X. ACS Catal. 2017, 7, 1087-1092.

http://pubs.acs.org/doi/abs/ 10.1021/acscatal.6b03211

9. Motika, S. E.; Wang, Q.; Ye, X.; Shi, X.Org. Lett. 2015, 17, 290-293.

http://pubs.acs.org/doi/abs/ 10.1021/ol503393a

10. Duan, H.; Sengupta, S.; Petersen, J. L.; Akhmedov, N.; Shi, X. J. Am. Chem. Soc. 2009, 131, 12100-12102. http://pubs.acs.org/doi/abs/ 10.1021/ja9041093

11. Wang, D.; Gautam, L. N. S.; Bollinger, C.; Harris, A.; Li, M.; Shi, X. Org. Lett. 2011, 13, 2618-2621. http://pubs.acs.org/doi/pdf/ 10.1021/ol200714h

12. Kumar, M,; Jasinski, J.; Hammond, G.B.; Xu, B. Chem. Eur. J. 2014, 20, 3113-3119. http://onlinelibrary.wiley.com/doi/ 10.1002/chem.201304271/abstract

13. Young, P.C.; Green, S.L.; Rosair, G.M.; Lee, A. Dalton Trans. 2013, 42, 9645-9653. http://pubs.rsc.org/en/Content/ArticleLanding/2013/DT/c3dt50653c\#!divAbstract

14 Stefani, H. A.; Cella, R.; Dörr, F. A.; de Pereira, C.M.P.; Gomes, F.P.; Zeni. G. Tetrahedron Lett. 2005, 46, 2001-2003

http://www.sciencedirect.com/science/article/pii/ S0040403905002303

15 Xie, C.; Liu, L.; Zhang, Y.; Xu, P. Org. Lett. 2008, 10, 2393-2396

http://pubs.acs.org/doi/10.1021/ol800651h

16 Kang, S.K.; Yoon, S.K.; Kim, Y.M. Org. Lett. 2001, 3, 2697-2699 http://pubs.acs.org/doi/10.1021/ol0162825

17 Bakthadoss, M.; Sivakumar, N.; Devaraj, A; Kumar. P.V. RSC Adv. 2015, 5, 93447-93451 http://pubs.rsc.org/en/content/articlepdf/2015/ra/c5ra14195h 